\title{
A opinião pública na produção literária e acadêmica de relações públicas no Brasil: 1960-20191
}

The public opinion in literary and academic production of public relations in Brazil: 1960-2019

La opinión pública en la producción literaria y académica de relaciones públicas en Brasil: 1960-2019

\section{Gustavo Eugênio Hasse Becker}

- Doutor em Comunicação Social pela Pontifícia Universidade Católica do Rio Grande do Sul (PUC-RS).

- Mestre em Comunicação Social pela PUC-RS.

- $\quad$ Especialista em Marketing pela Universidade Federal do Rio Grande do Sul (UFRGS).

- Graduado em Relações Públicas pela Universidade do Vale do Rio dos Sinos (Unisinos).

- Professor dos cursos de Comunicação e Marketing da Universidade Luterana do Brasil (Ulbra).

- Integra o Grupo de Pesquisa Ensino e Prática de Comunicação (GPEPcom), vinculado à PUC-RS.

- Integrou a gestão 2013/2015 do Conselho Federal de Profissionais de Relações Públicas (Conferp).

- Integrou as gestões 2004/2006 e 2007/2009 do Conselho Regional de Profissionais de Relações Públicas (Conrerp, $4^{\mathrm{a}}$ Região).

- E-mail:gustavohb@terra.com.br 


\section{Resumo}

Este artigo relata uma investigação que mapeou a produção literária e acadêmica de relações públicas no Brasil, buscando compreender as abordagens sobre o tema opinião pública no referido corpus. Uma consulta a bibliotecas universitárias, à Fundação Biblioteca Nacional e a programas de pós-graduação stricto sensu ocorreu para a coleta de dados, resultando na identificação de 20 livros e seis teses que discorreram sobre opinião pública, e de onde emergiram sete categorias com abordagens distintas sobre o tema.

\section{PALAVRAS-CHAVE: COMUNICAÇÃO • RELAÇÕES PÚBLICAS • OPINIÃO PÚBLICA • PRODUÇÃO LITERÁRIA • PRODUÇÃO ACADÊMICA.}

\section{Abstract}

This article reports an investigation that mapped the literary and academic production of public relations in Brazil to understand the approaches on the subject of public opinion in the referred corpus. A consultation with university libraries, the National Library Foundation, and stricto sensu graduate programs took place for data collection, resulting in the identification of 20 books and six dissertations that discussed public opinion, and from which seven categories with different approaches emerged on the topic.

\section{KEYWORDS: COMMUNICATION P PUBLIC RELATIONS •PUBLIC OPINION・LITERARY PRODUCTION・ACADEMIC PRODUCTION.}

\section{Resumen}

Este artículo presenta una investigación que mapeó la producción literaria y académica de las relaciones públicas en Brasil para comprender los enfoques sobre el tema de la opinión pública en el referido corpus. Para la recopilación de datos, se realizó una consulta en bibliotecas universitarias, en la Fundação Biblioteca Nacional y en programas de posgrado stricto sensu, la cual resultó la identificación de 20 libros y seis tesis que discutieron la opinión pública; de las cuales surgieron siete categorías con diferentes enfoques sobre el tema. 
A

investigação aqui relatada teve como objetivos mapear a produção literária e acadêmica de relações públicas no Brasil e compreender as abordagens sobre o tema opinião pública na referida produção.

O elemento motivador para o desenvolvimento deste estudo foi o fato de o tema opinião pública estar plenamente conectado com a atividade de relações públicas, desde o manifesto de lvy Lee, no início do século XX, até a menção e a destinação de espaço significativo à opinião pública nos documentos basilares que formalizam a atividade de relações públicas no Brasil². Não obstante, destaca-se a atualidade do tema e a inquietação que desencadeia frente ao cruzamento desenfreado de dados e hipotéticas informações, assim como os falsos dados, todos passíveis de fornecer elementos capazes de influenciar o modo de pensar, agir e construir a opinião dos cidadãos.

Para Fortes (2003, p.35), "trabalhar com a opinião pública, apesar das situações adversas, é para o profissional de relações públicas uma das razões da sua existência no processo social". Tal afirmação soa desafiadora, uma vez que, numa percepção empírica preliminar, inferiu-se que existisse pouca dedicação e aprofundamento no tema pelos produtores de literatura e pesquisa acadêmica vinculados à área das relações públicas no país.

Para o alcance dos objetivos, foi realizado um panorama da literatura de relações públicas publicada no Brasil. Na sequência, foi analisada a produção acadêmica (teses) gerada nos programas de pós-graduação em comunicação quemantêm linhas de pesquisa aderentes à investigação na área, o que gerou oindicativo das produções que abordam o tema opinião pública.

O passo seguinte foi a identificação e análise dos livros e teses de relações públicas que abordam a questão, de modo a se chegar à compreensão das abordagens sobre o tema, conforme os objetivos propostos.

\section{COMO SURGE E SE DESENVOLVE A OPINIÃO PÚBLICA}

Para uma melhor compreensão da relevância dos estudos sobre a opinião pública no contexto da sociedade atual, em alinhamento com o aquilo a que se propõe o presente estudo, é oportuno voltar-se à gênese dessas reflexões. Catto (2008) destaca que Platão aludia ao termo opinião distinguindo-o de conhecimento, na medida em que o primeiro não necessariamente condiz com a verdade, enquanto o segundo coaduna-se com a essência do saber. Complementarmente, Hohlfeldt ${ }^{3}$ destaca que, para Platão, na estrutura social da koiné(comunidade) evidenciava-se a prioridade ao desenvolvimento do conhecimento e a então consequente busca da sabedoria - algo restrito a muito poucos. Nesse contexto, essas poucas pessoas, ao desenvolver a ciência, tinham seu foco no ser, na busca pelo que é, de modo contrário à opinião que, na concepção de Platão, não passa de uma impressão exercida sobre a aparência do ser, podendo sofrer constantes modificações, constituindo um sentimento de segunda grandeza.

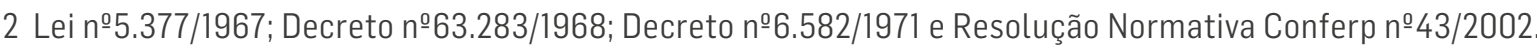

3 Apresentado pelo Prof. Dr. Antonio Hohlfeldt - pesquisador da área e docente da disciplina Comunicação e Opinião Pública do PPGCom da PUCRS - em 26 de abril de 2018, naquela IES. 
Platão ainda teria formulado o primeiro conceito de multidão, que seria o coletivo dos "amigos da opinião" (philodoxos) da qual emana a opinião. Tarde (2005), acrescentaria a esse conceito a ideia de que a multidão se caracteriza por um "feixe de contágios psíquicos" (2005, p. 6), que são gerados por contatos físicos, constituindo fator essencial na constituição do conceito.

Por fim, para Platão , o conhecimento é algo que emana de um contexto racional, não podendo constituir um processo emocional como seria o da constituição da opinião. Seria um processo filosófico, destinado a poucos, o que leva à percepção de que Platão pouco preconizava a participação do povo no processo político.

No entanto, se o sistema político se constituía de modo hierárquico para Platão, Aristóteles o concebia de modo horizontalizado. Silva (2016, p.50) constata que, para Aristóteles

[...] opiniões expressas nas discussões dialéticas e retóricas são constituídas por uma classe especial de opiniões conhecidas como endoxa, adjetivo grego que expressa não uma opinião qualquer, mas aquela ou aquelas opiniões [...] dos mais sábios ou eminentes ou opiniões comuns à maioria.

Em outras palavras, seriam as "opiniões geralmente aceitas" aquelas que concedem sustentação à argumentação dialética.

Maquiavel, reconhecido como fundador da ciência política moderna, demonstra perspicácia ao interpretar cenários, prever resultados, mapear reações e propor atitudes. Quando afirma que "Aqueles que apenas por sorte se tornam príncipes, pouco esforço fazem para isso, é claro, mas conservam-se muito dificultosamente [...]" (1977, p.37), demonstra atualidade no modo de interpretar a realidade. Ele alude ao poder do povo no processo de legitimação de um governante, afirmando que o povo elege um governante que o proteja e possa defendêlo "dos grandes". Acerca da base de sustentação de um governante, alerta: "Contra a hostilidade popular, não pode o príncipe jamais estar seguro, pois são muitos [...]" (1977, p. 57). Essa afirmação permite depreender que o autor estabelece um prenúncio de análise do que viria a se configurar como opinião pública e evidencia que, mesmo não havendo consenso nos desejos da sociedade, ela se organiza de modo a fazer prevalecerem as suas necessidades e anseios.

Esse e outros pensamentos de Maquiavel remetem ao processo de relações públicas, na medida em que 0 autor analisa os relacionamentos firmados entre um governante e os diversos públicos com os quais se relaciona, visando sua legitimação e o equilíbrio das tensões que se estabelecem em tal contexto.

Em alinhamento com essa percepção, é possível afirmar que Blumer (1978) dialoga com o pensamento expresso por Maquiavel, uma vez que esse entende ser a opinião pública um produto coletivo originado por aqueles que, ao somar suas opiniões, mesmo que não haja unanimidade, estarão aptos à tomada de uma decisão e à definição de um posicionamento. Segundo o autor, "A formação da opinião pública exige que as pessoas estejam abertas para partilhar a experiência do outro e se mostrem dispostas a fazer compromissos e concessões [...]" (1978, p.185). Assim, viabiliza-se um posicionamento coletivo, originado em opiniões individuais e que não necessariamente correspondem ao desejo da maioria, mas que correspondem à decisão advinda de tensionamentos e do poder de influência de grupos minimamente organizados e com interesses comuns.

Muitos pensadores se debruçaram sobre o tema opinião pública, especialmente entre os séculos XVII e XVIII. De origens diversas, com pontos de vista e a partir de disciplinas diversos, cada um desenvolveu suas reflexões sobre o tema. Sobre isso, Childs (1976, p.167) afirma: 
aos governos mais despóticos e militaristas, tanto quanto aos mais livres e populares. Blaise Pascal referiu-se à opinião como 'Rainha do Mundo', ao que Voltaire replicou: 'se a opinião é Rainha do Mundo, os filósofos governam a Rainha'. [...] E Rousseau [...] aplicou sua teoria da infalibilidade popular ao Estado, proclamando que 'o desejo mais generalizado é também o mais justo'.

A análise do tema opinião pública perpassa diversos campos do conhecimento, como o da sociologia, do direito e da psicologia, conforme destaca Childs (1976). 0 autor expressa, também, que Tarde, Wallas, Christensen, Lippmann e muitos outros salientaram o caráter emocional e irracional do processo formativo da opinião pública, ao mesmo tempo em que Jeremy Bentham destacou a opinião pública como meio de controle social e a sua articulação com as leis, da mesma forma que foi um dos primeiros a analisar a participação da imprensa na formação da opinião pública, enfoque até então não explorado. Mas foi a Revolução Francesa que desempenhou papel relevante nesse sentido, estimulando o debate a partir deste enfoque até então não ou minimamente explorado.

Dentre os diversos estudiosos anteriormente mencionados e, num momento em que se conferia grande importância ao sufrágio universal e a todas as demais formas de ação coletiva, surge um novo olhar, capaz de influenciar aquele momento e abrir uma perspectiva basilar e essencial para os estudos de opinião pública e para a compreensão de tal fenômeno, conforme é descrito a seguir.

Na introdução de A opinião e as massas, obra de 1901, de Gabriel Tarde, Dominique Reynié destaca que Tarde, professor, sociólogo, criminologista, psicólogo e filósofo francês, ao buscar reavaliar a política de massa, propõe os primeiros elementos de uma ciência da opinião pública, numa obra que acabou por representar um marco na teoria sociológica do grande número, com uma inscrição global contra a iminente desordem que a democracia de massa haveria de produzir (Tarde, 2005).

Para Tarde, público "[...] é uma coletividade puramente espiritual, como uma disseminação de indivíduos fisicamente separados e cuja coesão é inteiramente mental" (Tarde, 2005, p.5). 0 autor afirma que foi somente após o primeiro grande desenvolvimento da invenção da prensa, no século XVI, que o público pode começar a nascer, quando, então, se viu "[...] novidade profunda e de incalculável efeito, a leitura cotidiana e simultânea de um mesmo livro, a Bíblia, editado pela primeira vez em milhões de exemplares, dar à massa uniforme de seus leitores a sensação de formar um corpo social novo, separado da Igreja" (p.10). Com o surgimento do jornalismo, cuja gênese data da Revolução Francesa, consolidou-se tal constituição, nominada público.

Do legado de Tarde depreende-se que a opinião pública resulta da multiplicação dos julgamentos individuais, num trabalho de fusão das opiniões pessoais em opiniões locais e que, ao conquistar, através do jornalismo, a unificação do espírito público, expande-se internacionalmente.

A propósito do papel do jornalismo nesse processo, numa análise contemporânea do pensamento de Tarde, Hohlfeldt (2011, p.31), destaca:

[...] Gabriel Tarde acreditava que a imprensa (o meio massivo de comunicação mais poderoso existente na época) propiciava a socialização, transformando as massas eventualmente perigosas em grupos de opinião (hoje, diríamos grupos de pressão) graças ao fenômeno da conversação, promovida pela divulgação de diferentes informações através da imprensa.

Na percepção do autor, respeitadas as profundas e rápidas modificações decorrentes do surgimento das tecnologias e dos modernos meios de comunicação, essa teoria pode ser considerada válida ainda hoje, visto que:

Afinal, o sucesso da internet, do MSN e de tantas outras redes sociais de comunicação se deve justamente à inata curiosidade do homem e à sua ínfima necessidade de contactar seus semelhantes, coisas, aliás, já registradas desde Aristóteles, a quem sempre devemos voltar, quando pensamos no fenômeno eminentemente humano de comunicação. (Hohlfeldt, 2011, p.31) 
É possível que um dos legados mais relevantes de Tarde tenha sido o modo despojado como creditou à imprensa ${ }^{4}$ a capacidade e responsabilidade de formar e influenciar a opinião pública, dando vazão, assim, a essa questão. Tarde não terá sido o primeiro pensador a estabelecer tal relação, mas foi incisivo ao delinear essa condição na busca da sistematização desse processo.

Paralelamente, numa visão contemporânea sobre o tema, Habermas (2003) - um dos estudiosos da Escola de Frankfurt visualiza duas possibilidades de definição de opinião pública. A primeira tem na comunicação o elemento capaz de disseminar formadores de opinião em meio a um público "meramente aclamativo" (p. 276). A segunda possibilidade transpõe a materialidade, revestindo-se de "critérios institucionais", através dos quais, por exemplo, "A vontade dos partidos é idêntica à dos cidadãos ativos, de tal modo que, em cada caso, o partido da maioria representaria a opinião pública" (p.277). Na medida em que os frankfurtianos estudaram os impactos que as mensagens causam no comportamento das pessoas, Catto (2008) destaca que "Habermas, além de conceituar opinião pública, contextualiza sua formação e manipulação pelos meios de comunicação" (p.7). Ainda nesse contexto, Habermas alerta para o fato de que, ao retirar do público a condição de "sujeito da opinião pública", conferindo a ele apenas a capacidade de agir politicamente, o conceito aqui apresentado acaba por se revestir de uma significativa "neutralidade e peculiaridade" sujeita ao enfraquecimento e à redução de sua capacidade articuladora (p.278). Eis, portanto, uma demonstração da subordinação comportamental das pessoas ao poder da mídia, conforme a ideia defendida pelo autor.

Dos conceitos acima elencados, a partir da visão dos autores referidos, alguns elementos se somam, mostrando-se recorrentes, assim como demonstrando constituir a essência do processo da opinião pública, a saber: que ela se dá a partir do comportamento dos públicos ao fazerem prevalecer necessidades e anseios, tornando o ato coletivo e resultado da soma de opiniões, muito embora elas não sejam unânimes, mas, sim, frutos de negociações e da disposição em se fazer concessões. Paralelamente, todo o processo somente se articulou com efetividade e com a configuração hoje conhecida a partir da invenção da prensa e a consequente disseminação de informações massificadas - a mídia - capazes de influenciar pessoas sobre um mesmo tema, independentemente da localização geográfica dessas pessoas. Assim nasceram os públicos e, deles, emanou a opinião pública.

\section{A OPINIÃO PÚBLICA E AS RELAÇ̃̃ES PÚBLICAS}

De uma visão mais ampla sobre a opinião pública e partindo do fato de que tal fenômeno interessa e é estudado por distintas áreas do conhecimento, chega-se à aplicação do tema na área das relações públicas.

Nesse sentido, considerando a origem norte-americana da atividade, é relevante que se destaque o papel daquele que é considerado o pai intelectual das relações públicas: Edward Bernays, que publicou em 1923 a obra Crystallizing public opinion, precursora de mais de uma dezena de livros que contribuíram para o desenvolvimento da atividade nos Estados Unidos.

Muito embora muitas das práticas profissionais de Bernays tenham sido condenadas pelo ponto de vista ético, causando certa ambiguidade no reconhecimento do seu legado (Silva, 2017), não se pode tratar da relação opinião pública versus relações públicas sem que se faça menção às suas contribuições. Segundo Silva (2017, p.96), para Bernays

A opinião [...] não deve ser entendida como fruto de julgamentos individuais e tampouco como um constructo caracterizado de forma extrema como completamente moldável ou totalmente imutável. A opinião nunca é algo puro ou imaculado - ao contrário, ela é, ao mesmo tempo, parte e resultado de um processo complexo, modificada pelas circunstâncias e pelas transações entre públicos e práticas dotadas de intencionalidades diversas. 
Tais práticas, ainda segundo Silva (2017), tanto podem ser originadas por um veículo da mídia, por um político ou uma empresa, contando com o suporte de um profissional de relações públicas que, através da sua consultoria, proverá "outras vozes que sejam capazes de um maior impacto na formação da opinião" (p. 97), sejam elas através de eventos estratégicos, da sugestão de pauta ou da posterior publicação favorável a uma determinada causa, ou, até mesmo, a criação de estruturas institucionais capazes de suportar causas e/ou propósitos que visem a influenciar a opinião pública.

Registra-se, igualmente, aqui, o legado de Harwood Childs para a área, especialmente em virtude da sua penetração nas reflexões sobre o tema no contexto brasileiro e sua consequente contribuição para a discussão da relação existente entre relações públicas e opinião pública. A contribuição de Childs remonta ao ano de 1940, quando, nos Estados Unidos, publicou Relações públicas, propaganda e opinião pública. Naquela época, o Brasil dava os primeiros passos no campo das relações públicas, voltado à prática profissional, alimentando-se da produção intelectual estrangeira e da contribuição de profissionais igualmente estrangeiros que estabeleciam interlocução com os brasileiros que desbravavam a área. Assim, a obra de Childs chegou ao Brasil em 1964, influenciando os estudiosos brasileiros sobre o assunto, talvez de modo mais indelével do que outros autores até mesmo precursores a Childs e que trataram, igualmente, do tema.

Ao debruçar-se sobre a temática da opinião pública, Childs afirma que "Opinião pública e relações públicas são expressões que têm em comum o seu sentido bastante amplo e o fato de só se tornarem interessantes quando relacionadas com públicos específicos" (1976, p.57). Na mesma proporção em que considera indissolúvel o estudo da opinião pública e a prática das relações públicas, o autor alerta para as dificuldades e desafios desse processo, na medida em que o que está em jogo não é algo linear. Afirma, ainda, que um dos aspectos que mais pode perturbar é a crescente intensidade dos conflitos de opinião, de modo que seja provável que nenhum outro aspecto que envolva esse assunto desperte mais interesse do que o desafio de como obter o apoio da opinião pública. Para o autor, "opinião pública é qualquer coleção de opiniões individuais, independentemente do grau de concordância ou uniformidade" (1976, p.60). Essa convicção se soma a pensamentos anteriormente destacados, de outros autores, de modo que se depreende certa unanimidade conceitual.

Buscando abordagens brasileiras sobre o tema opinião pública que estabelecessem sintonia com a área de relações públicas, destaca-se Monique Augras, com a obra Opinião pública: teoria e pesquisa (1970). A autora parte do ponto de vista de que os estudos da opinião pública estão situados "no meio da psicologia social e da ciência política" (p.11), e os caracteriza como um processo multidisciplinar. Atrela as relações públicas às técnicas de gerenciamento da opinião pública e denota pleno alinhamento com o pensamento de Gabriel Tarde, ao afirmar que "A descrição histórica evidencia a existência da opinião como força, cuja expressão toma maior importância à medida que se desenvolvem os meios de informação e comunicação" (p.16). Assim, afirma que a mídia desempenha um papel fundamental na propagação do ideário que culmina na formação da opinião pública.

Da múltipla influência de áreas destacadas por Augras, ao refletir sobre o tema opinião pública, a autora (1974, p.17) destaca, de modo peculiar e abrangente:

O estudo da opinião pública, como fenômeno, implica o levantamento dos fatores psicológicos (opinião latente ao nível individual), sociológicos (opinião estática em nível social) e históricos (conscientização levando à opinião dinâmica). Necessário será também passar em revista os meios de expressão da opinião, que muitas vezes, se confundem com as técnicas de manipulação da opinião. (grifos nossos)

Augras alude de modo não explícito à prática de relações públicas, ao referir-se a "passar em revista os meios de expressão da opinião", na medida em que caberia a essa área o planejamento e a execução de estratégias capazes de sensibilizar e modificar a percepção da opinião pública relativa a fatores que demandam uma tomada de decisão ou posicionamento frente a questões 
postas. Contudo, soma-se às opiniões dos demais autores já referenciados, especialmente no que tange ao papel da mídia no processo de formação da opinião pública, assim como do planejamento de ações capazes de interferir na formação da opinião.

\section{O DESENVOLVIMENTO DO PROCESSO}

Os livros e teses que constituíram a base da investigação foram localizados e consultados junto a seis bibliotecas, sendo elas: a Fundação Biblioteca Nacional, do Rio de Janeiro; a da Escola de Comunicações e Artes da Universidade de São Paulo (USP); a Biblioteca Irmão José Otão, da Pontifícia Universidade Católica do Rio Grande do Sul (PUCRS); a da Faculdade de Biblioteconomia e Comunicação da Universidade Federal do Rio Grande do Sul (UFRGS); a da Universidade do Vale do Rio dos Sinos (Unisinos) e a da Universidade Luterana do Brasil (Ulbra). Aescolha dos espaços se deu de modo intencional, tendo sido utilizados os seguintes filtros: livros (impressos e eletrônicos) publicados no Brasil; de autores brasileiros; e que contivessem o sintagma relações públicas no título ou subtítulo. Num segundo momento, foi acrescido mais um critério para a definição das obras: que elas contivessem referência ao tema opinião pública em seu conteúdo.

Com relação à produção acadêmica, foram eleitas as teses desenvolvidas junto aos programas de pós-graduação stricto sensu brasileiros que mantêm linhas de pesquisa aderentes à área de relações públicas, mantendo-se os mesmos critérios de filtro utilizados na seleção dos livros. Os programas são vinculados às seguintes instituições: Universidade Católica de Brasília (UCB), Universidade de Brasília (UnB), Universidade de São Paulo (USP), Universidade Federal de Santa Maria (UFSM), Universidade Federal do Rio Grande do Sul (UFRGS), Universidade Metodista de São Paulo (UMESP), Pontifícia Universidade Católica de Minas Gerais (PUC-MG) e Pontifícia Universidade Católica do Rio Grande do Sul (PUC-RS).

De um universo de 170 livros e 37 teses levantados na investigação, 20 livros (vide Quadro 1) e seis teses apresentaram referência ao tema opinião pública, constituindo o corpus definitivo da investigação - que teve a predominância da análise qualitativa (Richardson, 1999) valendo-se do suporte da análise textual discursiva (Moraes, 2002).

Após o manuseio e identificação dos conteúdos relacionados à opinião pública, junto aos livros e teses, foi realizada sua desconstrução, ocasionando a etapa de categorização que, segundo Bardin (1977, p.117), "[...] é uma operação de classificação de elementos constitutivos de um conjunto, por diferenciação e, seguidamente, por reagrupamento segundo o gênero (analogia) [...]".

Do processamento dos fragmentos retirados das 26 obras em questão, considerando as abordagens assim como os referenciais teóricos apresentados pelos seus autores, os 211 fragmentos foram distribuídos em sete categorias por mim propostas, conforme segue descrito na Tabela 1.

Tabela 1: Categorias e os fragmentos identificados

\begin{tabular}{|c|c|}
\hline Categorias & Fragmentos \\
\hline Opinião pública contextualizada & 25 \\
\hline $\begin{array}{c}\text { Opinião pública como } \\
\text { instância de mando, tomada } \\
\text { de decisão e de julgamento }\end{array}$ & 24 \\
\hline $\begin{array}{c}\text { Opinião pública resultante da ação } \\
\text { dos meios de comunicação e de } \\
\text { outros artefatos comunicacionais }\end{array}$ & 36 \\
\hline
\end{tabular}


Tabela 1: Continuação

\begin{tabular}{|c|c|}
\hline Categorias & Fragmentos \\
\hline $\begin{array}{c}\text { Opinião pública resultante de } \\
\text { um processo psicossocial }\end{array}$ & 27 \\
\hline $\begin{array}{c}\text { Opinião pública resultante de um } \\
\text { processo coletivo, não unânime }\end{array}$ & 55 \\
\hline $\begin{array}{c}\text { Opinião pública resultante de um } \\
\text { processo internacional/mundial }\end{array}$ & 9 \\
\hline $\begin{array}{c}\text { Opinião pública e a ação } \\
\text { de relações públicas }\end{array}$ & 35 \\
\hline TOTAL & 211 \\
\hline
\end{tabular}

Fonte: elaborada pelo autor.

É relevante destacar que, em alguns casos, uma mesma obra conteve fragmentos que compuseram mais de uma das categorias acima relacionadas. Contudo, nenhuma obra teve fragmentos relacionados a todas as categorias. 0 mesmo ocorreu, também, com as teses analisadas.

A última etapa do processo de análise textual levou aos desdobramentos que são explicitados na sequência.

\section{A OPINIÃO PÚBLICA: DO EMPÍRICO AO TEÓRICO}

Quase a metade (45\%) dos livros de relações públicas que abordam o tema opinião pública, segundo os critérios estabelecidos na investigação, pode ser encontrada nas seis bibliotecas consultadas, fato que denota a relevância das obras no contexto geral e junto aos acervos. A incidência destes livros tem a concentração de publicação nas décadas de 1960 e 1970, tornandose mais escassos nas décadas seguintes, conforme pode ser observado no Quadro 1.

Quadro 1: Produção bibliográfica5 abordando o tema opinião pública e os autores referenciados

\begin{tabular}{|c|c|c|c|c|}
\hline Título & Autor & Ano & Fragmentos & Referências sobre opinião pública \\
\hline $\begin{array}{l}\text { Para Entender } \\
\text { Relações Públicas }\end{array}$ & $\begin{array}{l}\text { Cândido Teobaldo } \\
\text { de Souza Andrade }\end{array}$ & 1962 & 15 & $\begin{array}{c}\text { David Hume } \\
\text { José Ortega y Gasset } \\
\text { Alfred Sauvy } \\
\text { Eric Johnson } \\
\text { Gabriel Tarde } \\
\end{array}$ \\
\hline $\begin{array}{l}\text { Aspectos de Relações } \\
\text { Públicas }\end{array}$ & Sylla Magalhães Chaves & 1963 & 3 & $\begin{array}{l}\text { Harwood Childs } \\
\text { Bertrand Canfield }\end{array}$ \\
\hline $\begin{array}{l}\text { Relações Humanas, } \\
\text { Liderança, Relações } \\
\text { Públicas }\end{array}$ & Uirpy Benício & 1963 & 18 & $\begin{array}{c}\text { Edward Bernays } \\
\text { Walter Lippmann } \\
\text { Maurício Lima e Silva }\end{array}$ \\
\hline
\end{tabular}


Quadro 1: Continuação

\begin{tabular}{|c|c|c|c|c|}
\hline Título & Autor & Ano & Fragmentos & Referências sobre opinião pública \\
\hline $\begin{array}{l}\text { Relações } \\
\text { Humanas: Pequeno } \\
\text { Tratado - Relações } \\
\text { Públicas, Liderança, } \\
\text { Psicologia Social }\end{array}$ & $\begin{array}{l}\text { Fernanda Augusta Vieira } \\
\text { Ferreira Barcellos }\end{array}$ & 1965 & 11 & $\begin{array}{l}\text { Jerome Dowd } \\
\text { Gustave Le Bon } \\
\text { Gabriel Tarde } \\
\text { Walter Lippmann }\end{array}$ \\
\hline $\begin{array}{l}\text { Relações Públicas nas } \\
\text { Empresas Modernas }\end{array}$ & \begin{tabular}{|l} 
José Roberto \\
Whitaker Penteado
\end{tabular} & 1968 & 17 & - \\
\hline $\begin{array}{l}\text { Curso de Relações } \\
\text { Públicas }\end{array}$ & $\begin{array}{l}\text { Cândido Teobaldo } \\
\text { de Souza Andrade }\end{array}$ & 1970 & 21 & $\begin{array}{c}\text { Walter Lippmann } \\
\text { Franco Montoro } \\
\text { Harwood L. Childs } \\
\text { David Hume } \\
\text { John Locke } \\
\text { José Ortega Y Gasset } \\
\text { Napoleão Bonaparte } \\
\text { Abraham Lincoln } \\
\text { Alfred Sauvy } \\
\text { Eric Johnson } \\
\text { Juscelino Kubitschek de Oliveira } \\
\text { Darcy Azambuja }\end{array}$ \\
\hline $\begin{array}{l}\text { Comunicação Social e } \\
\text { Relações Públicas }\end{array}$ & Walter Ramos Poyares & 1970 & 14 & $\begin{array}{c}\text { Harwood L. Childs } \\
\text { Pascal } \\
\text { Carlos Cossio } \\
\text { C. R. Cooley } \\
\text { Frederick Iron } \\
\text { Leonar Doob } \\
\text { Edward Alsworth Ross } \\
\text { Floyd Alport } \\
\text { Juan Beneyto } \\
\text { Vitaliano Rovigatti } \\
\end{array}$ \\
\hline Relações Públicas & $\begin{array}{l}\text { Márcio César } \\
\text { Leal Coqueiro }\end{array}$ & 1971 & 15 & $\begin{array}{c}\text { Pascal } \\
\text { Voltaire } \\
\text { Jean-Jacques Rousseau }\end{array}$ \\
\hline $\begin{array}{l}\text { Usos e Abusos de } \\
\text { Relações Públicas }\end{array}$ & José Xavier de Oliveira & 1971 & 2 & Cândido Teobaldo de Souza Andrade \\
\hline $\begin{array}{l}\text { Relações Públicas: } \\
\text { Teoria e Processo }\end{array}$ & Martha Alves D'Azevedo & 1971 & 1 & - \\
\hline $\begin{array}{l}\text { Relações Públicas: } \\
\text { Fundamentos e Legislação }\end{array}$ & $\begin{array}{l}\text { Marcos Fernando } \\
\text { Evangelista }\end{array}$ & 1975 & 2 & Harwood Childs \\
\hline
\end{tabular}

Continua... 
Quadro 1: Continuação

\begin{tabular}{|c|c|c|c|c|}
\hline Título & Autor & Ano & Fragmentos & Referências sobre opinião pública \\
\hline $\begin{array}{l}\text { Psicossociologia das } \\
\text { Relações Públicas }\end{array}$ & $\begin{array}{l}\text { Cândido Teobaldo } \\
\text { de Souza Andrade }\end{array}$ & 1975 & 24 & $\begin{array}{c}\text { Nicolau Maquiavel } \\
\text { Jean-Jacques Rousseau } \\
\text { David Hume } \\
\text { Napoleão Bonaparte } \\
\text { Talleyrand } \\
\text { Abraham Lincoln } \\
\text { José Ortega Y Gasset } \\
\text { Papa Pio XII } \\
\text { Walter Lippmann } \\
\text { Gustave Le Bom } \\
\text { Gabriel Tarde }\end{array}$ \\
\hline $\begin{array}{l}\text { O Processo de } \\
\text { Relações Públicas }\end{array}$ & Hebe Wey & 1983 & 12 & Abraham Lincoln \\
\hline $\begin{array}{l}\text { Curso Básico de } \\
\text { Relações Públicas }\end{array}$ & $\begin{array}{l}\text { Fernanda Augusta Vieira } \\
\text { Ferreira Barcellos }\end{array}$ & 1984 & 13 & $\begin{array}{l}\text { Napoleão Bonaparte } \\
\text { Gabriel Tarde } \\
\text { Harwood Childs; } \\
\text { José Ortega Y Gasset } \\
\text { Alfred Sauvy } \\
\text { Eric Johson }\end{array}$ \\
\hline $\begin{array}{l}\text { Relações Públicas para } \\
\text { Clientes e Profissionais }\end{array}$ & Nelson Speers & 1986 & 2 & Cândido Teobaldo de Souza Andrade \\
\hline $\begin{array}{l}\text { Afinal, Que é } \\
\text { Relações Públicas? }\end{array}$ & Salma Salem Zogbi & 1987 & 2 & - \\
\hline $\begin{array}{l}\text { Relações Públicas: } \\
\text { Processo, Funções, } \\
\text { Tecnologia e Estratégias }\end{array}$ & Waldyr Gutierrez Fortes & 1988 & 18 & $\begin{array}{c}\text { Cândido Teobaldo de Souza Andrade } \\
\text { James Grunig } \\
\text { Robert Lane e David Sears } \\
\text { Raymond Simon } \\
\text { Sara Chucid Da Viá }\end{array}$ \\
\hline $\begin{array}{l}\text { Relações Públicas } \\
\text { para Executivos }\end{array}$ & $\begin{array}{l}\text { Reynaldo de } \\
\text { Miranda Leão }\end{array}$ & 2001 & 13 & $\begin{array}{c}\text { Carl Jung } \\
\text { Harwood Childs } \\
\text { Eric Carlson } \\
\end{array}$ \\
\hline $\begin{array}{l}\text { Relações Públicas } \\
\text { na Construção da } \\
\text { Responsabilidade } \\
\text { Histórica e no Resgate } \\
\text { da Memória Institucional } \\
\text { das Organizações }\end{array}$ & Paulo Nassar & 2007 & 1 & Walter Lippmann \\
\hline
\end{tabular}


Quadro 1: Continuação

\begin{tabular}{|l|c|c|c|c|}
\hline \multicolumn{1}{|c|}{ Título } & Autor & Ano & Fragmentos & Referências sobre opinião pública \\
\hline $\begin{array}{l}\text { Respeitável Público: } \\
\begin{array}{l}\text { Relações Públicas } \\
\text { e a Força Invisível } \\
\text { dos Negócios }\end{array}\end{array}$ & Antônio Ernesto de Salvo & 2012 & 2 & \\
\hline
\end{tabular}

Fonte: elaborado pelo autor.

Assim como o primeiro livro de relações públicas que aborda o tema opinião públicapublicado no Brasil por um autor brasileiro foi em 1962, a primeira tese de relações públicas que contém abordagem ao tema opinião pública foi defendida no Brasil em 1972, na área de relações públicas. Explico a coincidência: o livro e a tese possuem o mesmo autor: Candido Teobaldo de Souza Andrade.

Das seis teses que abordam o tema opinião pública, uma foi desenvolvida na década de 1970, outra na década de 1980, mais uma na década de 1990 e três foram desenvolvidas da década de 2000, conforme exposto no Quadro 2.

Quadro 2: Teses que abordam o tema opinião pública e os autores referenciados

\begin{tabular}{|c|c|c|c|c|}
\hline Título & Autor & Ano & Fragmentos & Referências sobre opinião pública \\
\hline $\begin{array}{l}\text { Relações Públicas e } \\
\text { o Interesse Público }\end{array}$ & $\begin{array}{l}\text { Cândido Teobaldo } \\
\text { de Souza Andrade }\end{array}$ & 1972 & 24 & $\begin{array}{c}\text { David Hume } \\
\text { Napoleão Bonaparte } \\
\text { Charles-Maurice de Talleyrand-Périgord } \\
\text { Abraham Lincoln } \\
\text { José Ortega y Gasset } \\
\text { Papa Pio XII } \\
\text { Walter Lippmann } \\
\text { James T. Young } \\
\text { Gustave Le Bom } \\
\text { Gabriel Tarde } \\
\text { Arthur Ramos }\end{array}$ \\
\hline $\begin{array}{l}\text { Relações Públicas } \\
\text { como Instrumental } \\
\text { da Administração da } \\
\text { Controvérsia Pública - } \\
\text { Estudos de caso }\end{array}$ & $\begin{array}{l}\text { Francisco Assis } \\
\text { Martins Fernandes }\end{array}$ & 1985 & 21 & $\begin{array}{c}\text { Cândido Teobaldo de Souza Andrade } \\
\text { Harwood Childs } \\
\text { Edward Bernays } \\
\text { David Hume } \\
\text { James Bryce } \\
\text { José Marques de Melo } \\
\text { José Roberto Whitaker Penteado } \\
\text { Sam Black } \\
\text { Sara Chucid Da Viá } \\
\text { Wright Mills }\end{array}$ \\
\hline
\end{tabular}


Quadro 2: Continuação

\begin{tabular}{|c|c|c|c|c|}
\hline Título & Autor & Ano & Fragmentos & Referências sobre opinião pública \\
\hline $\begin{array}{l}\text { Relações públicas e a } \\
\text { comunicação dirigida }\end{array}$ & $\begin{array}{l}\text { Cleuza Gertrudes } \\
\text { Gimenes Cesca }\end{array}$ & 1994 & 11 & $\begin{array}{c}\text { Cândido Teobaldo de Souza Andrade } \\
\text { Marcos Fernando Evangelista } \\
\text { Harwood Childs }\end{array}$ \\
\hline $\begin{array}{l}\text { A relação do Estado, } \\
\text { da Sociedade e do } \\
\text { Mercado na Construção } \\
\text { da Cidadania. O Papel } \\
\text { das Relações Públicas } \\
\end{array}$ & $\begin{array}{l}\text { Maria José da } \\
\text { Costa Oliveira }\end{array}$ & 2001 & 8 & $\begin{array}{c}\text { José Marques de Melo } \\
\text { Rubens Figueiredo } \\
\text { José Roberto Whitaker Penteado } \\
\text { Cândido Teobaldo de Souza Andrade }\end{array}$ \\
\hline $\begin{array}{l}\text { Relações Públicas: } \\
\text { Estratégia de } \\
\text { Relacionamentos com } \\
\text { Públicos Específicos } \\
\end{array}$ & Fábio França & 2002 & 5 & - \\
\hline $\begin{array}{l}\text { A Validação } \\
\text { dos Princípios } \\
\text { Organizacionais por Meio } \\
\text { da Atuação das Relações } \\
\text { Públicas nos Processos } \\
\text { Comunicacionais }\end{array}$ & Júlio César Barbosa & 2007 & 8 & $\begin{array}{c}\text { James Grunig } \\
\text { Lucien Matrat } \\
\text { Hebe Wey }\end{array}$ \\
\hline
\end{tabular}

Fonte: elaborado pelo autor.

Vale destacar o fato de que as seis teses em questão correspondem a pouco menos de $1 / 4(23 \%)$ das teses em que se enquadravam nos critérios iniciais estabelecidos para a investigação, lembrando que todas foram defendidas na Escola de Comunicações e Artes da Universidade de São Paulo (ECA-USP).

0 último estudo que aborda opinião pública encontrado na produção acadêmica data de 2007 - fato que soa contraditório, na medida em que o tema está diuturnamente em pauta, seja nas questões relacionadas ao poder público, na discussão da atuação de organizações no âmbito privado ou, mais do que nunca, nos fatos resultantes das relações pouco republicanas entre o poder público e a iniciativa privada. Contudo, é sabido que o tema opiniãopública pode estar presente na produção acadêmica vinculada aos estudos de comunicação organizacional, porém sem exagero nessa ênfase.

A seguir, apresenta-se o detalhamento das categorias emergentes da análise textual, conforme segue.

Dos 20 livros analisados, dez apresentam a preocupação de, ao tratar do tema opinião pública, estabelecer uma contextualização sobre ela antes mesmo de qualquer outra abordagem que possam dar ao fenômeno. Da mesma forma, quatro teses apresentam semelhante procedimento. Assim, a categoria opinião pública contextualizada é composta por 25 fragmentos, sendo 17 originados nos livros e oito nas teses. Da fusão deles, resulta o texto a seguir.

Nessa categoria destaca-se o interesse de políticos e organizações pela opinião pública, indicador encontrado no pensamento de Aristóteles, que entende que decisões políticas são tomadas a partir das opiniões geralmente aceitas num contexto de relações sociais estabelecidas e fundamentadas a partir daquelas opiniões. Também Maquiavel pode ser tomado como referência nesse contexto, ao sugerir que se perpetuam em sua conjuntura somente aqueles que, com perspicácia, conseguem interpretar cenários e, deles, estabelecem suas estratégias de ação (Maquiavel, 1977). Considerando os interesses relacionais 
e políticos das organizações, os fragmentos que compuseram a categoria em análise encontram sustentação também em Monique Augras, dado que a autora resgata a necessidade das organizações de manterem boas relações com diversos setores da opinião pública (Augras, 1974). Não diferente, Harwood Childs (1976) destaca a importância da opinião pública como fator político, aludindo a um ministro francês que apontou a importância da área nos estudos ligados à função pública.

Presente em oito livros e duas teses, a abordagem da opinião pública como instância de mando, tomada de decisão e de julgamento é tema recorrente entre as obras consultadas, totalizando 24 fragmentos -19 deles originados dos livros e cinco das teses.

Juízo, no sentido de julgamento e tomada de decisão, é o elemento que confere sustentação à segunda categoria. Tais indicadores encontram base em Platão quando, ao formular o conceito de multidão, sugere que ela seria o coletivo dos "amigos da opinião" - a origem da opinião e, consequentemente, da instância na qual se dão tomadas de decisão e julgamento. Maquiavel (1977), por sua vez, lembra que um príncipe jamais poderá estar seguro contra a hostilidade popular, dada a dimensão incerta dos ajuntamentos humanos. Portanto, evidencia-se, também, a partir do posicionamento desse autor, o poder popular - e da opinião pública - num processo de julgamento e tomada de decisão. Quando, a partir do legado de Gabriel Tarde (2005), se depreende que a opinião pública resulta da multiplicação dos julgamentos individuais, num trabalho de fusão das opiniões locais, regionais e assim por diante, é possível situar também esse autor como base para a discussão da categoria em questão. Por fim, Monique Augras (1974) também pode ser associada aos autores mencionados, na medida em que alude a técnicas que levem a sensibilizar e modificar a percepção da opinião pública, relativamente a fatores que demandam tomada de decisão ou posicionamento.

Com incidência em 13 livros e quatro teses, a estreita relação dos meios de comunicação com a formação da opinião pública é algo relevante e significativo no material consultado. Foram localizados 35 fragmentos ligados ao assunto, sendo 28 originados nos livros e sete nas teses. Da fusão desses fragmentos resulta o texto que segue:

A terceira categoria, Opinião pública resultante da ação dos meios de comunicação e de outros artefatos comunicacionais, tem como indicadores as discussões, os meios de comunicação e a imprensa. Tais rastros são encontrados primeiramente em Tarde (2005), que identifica na invenção da prensa o surgimento do fenômeno público, no sentido de uma "coletividade puramente espiritual" formada por indivíduos separados fisicamente, mas alinhados numa "coesão mental" (p.5). 0 autor menciona o surgimento do jornalismo, por ocasião da Revolução Francesa, como gênese da opinião pública, na medida em se tornou possível, pela leitura de uma mesma publicação, em locais e ambientes distantes e diversos, a constituição de um posicionamento que passa a ser coletivo. Alinhada com Tarde, e sob a sua influência, Monique Augras (1974) afirma que, na medida em que os meios de informação e comunicação se desenvolvem, torna-se mais expressiva a existência da opinião como um fenômeno de força e com potencial de suporte para uma tomada de posição coletiva, fato que caracteriza a opinião pública.

Alguns dos livros e teses, especialmente os das primeiras décadas de produção, apresentam uma abordagem com viés psicossocial. Tal fato ficou ainda mais evidente por ocasião da busca pela abordagem relacionada ao tema, quando foram localizados 27 fragmentos ligados ao assunto, sendo 24 originados em nove livros e três em uma tese, conforme a síntese a seguir.

Atitudes coletivas, crenças e meio cultural são os indicadores da quarta categoria, Opinião pública resultante de um processo psicossocial, que encontra seu primeiro respaldo em Platão, que diferencia conhecimento de opiniãoe afirma que a última constitui um processo emocional. Tarde (2005) acrescentará o caráter irracional a esse fenômeno, afirmando que, tendo em vista que os entes constituintes da opinião pública são influenciados pelos meios de comunicação, eles também exercem o seu poder formador de opinião. Em alinhamento com as convicções acima expressas, Harwood Childs (1976) resgata elementos da cultura e do ambiente como fatores capazes de auxiliar na formação das opiniões. Assim, em última instância, sugere 
que se encontra a causa da opinião pública na herança biológica, física, social e psicológica. A todos esses pensamentos, soma-se Augras (1974, p.17), afirmando que "[...] o estudo da opinião pública implica o levantamento dos fatores psicológicos, sociológicos e históricos", corroborando, teoricamente, os achados empíricos da presente investigação.

Com incidência em 12 livros e três teses, a Opinião pública resultante de um processo coletivo, não unânimeconstitui a maior categoria derivada do material consultado, com 55 fragmentos, sendo 39 originados nos livros e 16 nas teses. Contudo, apesar do número significativo de fragmentos da categoria, muitos deles se assemelham, denotando percepções muito similares, além da repetição efetiva de fragmentos em virtude da mesma autoria - de livro e tese - em um caso específico. 0 texto que segue resulta da fusão destes fragmentos.

A categoria Opinião pública resultante de um processo coletivo, não unânime traz como indicadores as opiniões grupais, o produto coletivo e o consenso utópico. Em alinhamento com os elementos basilares desta categoria, Tarde, ao referir-se a um trabalho de fusão das opiniões individuais, confere sustentação a esse fenômeno coletivo, destacando a "tomada de partido em suas disputas", por parte da opinião, na medida em que essa "embriaga-se com as novas doutrinas da moda" (2005, p.61). Aludindo à crescente intensidade dos conflitos de opinião - o que remete a um consenso utópico - Childs considera a possibilidade de que esse seja um dos aspectos mais perturbadores do contexto que cerca os estudos sobre opinião pública. 0 autor (1964, p. 60) ainda acrescenta que, "[...] independentemente do grau de concordância ou uniformidade, a opinião pública resulta da coleção de opiniões individuais". Na medida em que se identifica um absoluto alinhamento das convicções de Childs com as de Tarde, depreende-se a influência sofrida daquele por esse, conferindo sustentação a significativas análises teóricas sobre a opinião pública.

Com incidência em cinco livros e uma tese, Opinião pública resultante de um processo internacional/mundialconstitui a menor das sete categorias. No total, nove fragmentos abordam o tema, sendo oito deles originados de cinco livros e um de uma tese.

A penúltima categoria constituída na investigação, juntamente com seus indicadores - informações entre todas as partes do mundo e alicerce da humanidade -, trata da condição muito peculiar de que goza a opinião pública, especialmente nos dias de hoje, dada a mescla das fronteiras e a proliferação de informações, mundo afora, quase que em tempo real. Tudo isso, conforme destaca Tarde, graças à "significativa obra do jornalismo", que possibilita o acesso da informação aos mais longínquos recantos, levando ao que Tarde chama de "internacionalização do espírito público" (2005, p.69). Tal fenômeno, segundo 0 autor, tem sua origem na transformação das opiniões pessoais em opiniões locais, que passam a ser opiniões nacionais e que, por fim, constituem opiniões mundiais. Nada desse processo seria possível sem o alcance oportunizado pelos meios de comunicação, numa alusão à terceira categoria deste estudo. Hoje, de modo intenso, todosos recursos digitais, assim como as mais distintas redes sociais, são elementos fundamentais e incontestáveis para a consolidação da Opinião pública resultante de um processo internacional/mundial.

Com incidência em sete livros e quatro teses, o papel das relações públicas no processo de formação e gerenciamento da opinião pública é algo relevante e significativo no material consultado. Ao todo, foram localizados 35 fragmentos ligados ao assunto, sendo 28originados nos livros e sete nas teses. Da fusão desses fragmentos, resulta o texto quesegue.

Opinião pública e a ação de relações públicas, juntamente com o aspecto da mediação entre a organização e a opinião pública, constituem a última categoria decorrente dos resultados da investigação aqui relatada. Essa categoria propõe uma ação aplicada da atividade de relações públicas junto à opinião pública. Da fundamentação teórica construída, Maquiavel pode ser resgatado na medida em que analisa os relacionamentos estabelecidos entre um governante e os diversos públicos com os quais ele se relaciona, buscando o equilíbrio de tensões, assim como visando sua legitimação. Isso nada mais é do que a exegese do processo de relações públicas. Paralelamente, Childs considera indissolúvel o estudo da opinião pública e a 
prática das relações públicas, embora não se esteja tratando de um processo linear, o que remete a inquestionáveis desafios, uma vez que "as relações entre os grupos estão em constante transformação", além do fato de que "as condições variam e os públicos são diferentes" (1976, p.58). Em sintonia com Maquiavel e Childs, Augras caracteriza as relações públicas como uma prática junto a grupos aos quais uma organização não pode se opor "[...] a fim de manter boas relações com os diversos setores da opinião pública" (1974, p.77). Da mesma forma, a autora afirma caber às relações públicas sensibilizar e modificar a percepção da opinião pública através do planejamento e da execução de estratégias adequadas para tal finalidade.

Resgatados os resultados empíricos que constituíram as sete categorias que emergiram da investigação, foi possível cruzar os referidos achados com as escolhas teóricas indicadas anteriormente, estabelecendo-se a aquiescência da teoria elegida para fundamentar as reflexões e análises apresentadas.

\section{ENCAMINHAMENTOS}

Do ponto de vista da contribuição que a investigação aqui relatada possa ter trazido para a comunidade científica, destacase: o mapeamento da produção bibliográfica brasileira junto a seis das principais bibliotecas do país; o mapeamento da produção acadêmica brasileira, considerando teses defendidas em programas de pós-graduação que mantêm linhas de pesquisa aderentes à área de relações públicas; a construção de um panorama dessa produção, seguido da identificação das abordagens sobre opinião pública em tal referencial, resultando na proposição de sete categorias de análise sobre o tema, assim como o mapeamento dos autores e demais personalidades que influenciaram a abordagem sobre opinião pública em tais produções. Disto resultaram as considerações a seguir.

Nas produções brasileiras de relações públicas, o tema opinião pública é abordado em 45\% dos livros investigados e em $23 \%$ das teses. Assim, depreende-se não ser intenso o interesse pelo assunto, especialmente no âmbito dos programas de pós-graduação, quando observadas as produções bibliográficas. Tal fato se assemelha aos resultados de estudo realizado por Farias (2019), junto a periódicos, teses, dissertações e livros sobre opinião pública, em 11 grandes áreas do conhecimento, do qual resulta a observação que segue:

A comunicação organizacional possui pouca representatividade em relação aos estudos sobre opinião pública, uma vez que corresponde a 4\% de toda a produção científica dos últimos 15 anos. Nesse ponto, vale a ressalva em relação à importância da opinião pública para os estudos e a atuação profissional no campo das relações públicas e da comunicação organizacional, o que gera surpresa. (FARIAS, 2019, p.99)

Chama atenção o fato de, com o passar dos anos, o tema ter se tornando escasso nas obras investigadas, muito embora seja pulsante no cotidiano profissional. Neste sentido, Farias (2019, p.99) levanta a hipótese de ao invés de ser objeto "de pesquisas e produções científicas", o tema ser abordado em materiais por assim dizer técnicos, de uso aplicado à prática profissional. Considerando-se o viés operacional que, por vezes ainda prevalece na área ainda, tal inferência pode ser considerada procedente.

Nos livros em que há menção à opinião pública, diversos conceitos se repetem, levando a crer que os autores não buscam aprofundar o tema, mas sim valem-se daquilo que outros publicaram. A repetição de conceitos/abordagens em cada categoria transmite a ideia de que uma obra foi influenciando outra, não tendo surgido nada mais realmente novo.

Relativamente às teses, somente as da Escola de Comunicações e Artes da USP fazem referência à opinião pública, configurandose o único programa de pós-graduação do país a apresentar produção acadêmica sobre o tema. No entanto, as teses pouco se aprofundam e muitas o fazem-no de modo empírico, a partir das vivências ou convicções pessoais de seus autores. 
Quanto a autores referenciados nos livros e teses, há uma significativa pulverização e, em muitos casos, personalidades políticas ou da história são resgatadas para conferir sustentação a conceitos sobre opinião pública, fato que chama a atenção, pois, em contrapartida, poucos autores clássicos são referenciados.

Nos livros analisados, o predomínio é de um autor da área de relações públicas-Harwood Childs - em detrimento de autores basilares que tratam do tema, e outro autor da área - Cândido Teobaldo de Souza Andrade - considerado referência brasileira nas relações públicas, ocupa as primeiras posições dentre os mais citados.

Em relação ao tema opinião pública, autores brasileiros passaram a ser fonte de referência para os signatários das obras examinadas, sendo que, nas teses, Andrade é o autor que mais aparece. Tal fato demonstra certa acomodação dos autores das teses - e, em alguns casos, também dos livros - que findam trazendo Andrade para fundamentar suas reflexões, não ousando um aprofundamento conceitual em autores basilares. Isso, possivelmente, ocorre pelo fato de Andrade ter sido o pioneiro na produção brasileira, tanto bibliográfica quanto acadêmica, a abordar o tema opinião pública, inclusive em suas produções inaugurais. Por outra perspectiva, pode ter contribuído para isso o fato de, na década de 1970, com o livro Usose abusos de relações públicas, José Xavier de Oliveira ter sinalizado Andrade como referência teórica para o tema. As análises realizadas indicam que essa prática passou a ser frequente nas publicações subsequentes. Outro fator, relativo a Teobaldo Andrade, é que ele é o autor - dentre as obras investigadas - que mais escreveu sobre opinião pública.

Em busca de elementos a serem destacados a partir da investigação realizada, percebe-se que, mesmo que tenha constituído a menor das categorias analisadas, o viés internacional e mundial da opinião pública é algo tido em nossos dias como procedente. Afinal, do mesmo modo como a economia está globalizada, também a opinião pública é capaz de sofrer abalos ou protagonizar ações cujos reflexos podem ser percebidos no outro lado do planeta, praticamente em tempo real. Aqui, vale destacar que, muito embora o presente estudo tenha trabalhado com dados quantitativos, tanto para identificar a incidência de autores junto à produção analisada quanto para agregar os fragmentos das categorias nele propostas, a relevância dos achados se dá pelo viés qualitativo. Assim, torna-se secundária a quantidade de fragmentos que compuseram cada categoria, até porque houve categorias em que os fragmentos se repetiam - ou se assemelhavam -, na medida em que houve a reincidência dos autores referenciados.

Ainda, relativo ao viés internacional e mundial da opinião pública, as constatações emergentes dessa categoria estabelecem relação direta com outra, que atribui aos meios de comunicação o poder de formar e influenciar a opinião pública. Tal fato remete a Gabriel Tarde, muito embora o autor seja pouco referenciado nas produções. Paralelamente, assim como os meios de comunicação se tornaram o grande elemento difusor das opiniões e, de certo modo, os responsáveis pela nova configuração da opinião pública, também eles são capazes, nos dias atuais, de difundir elementos que podem levar a confundir a opinião pública a partir do estabelecimento de dados que não condizem com os fatos. Assim, os mesmos meios de comunicação capazes de formar a opinião púbica podem levá-la à tomada equivocada de decisão.

A investigação evidenciou a relevância do tema opinião pública para a área de relações públicas, corroborando o vínculo existente entre as áreas. Ainda, o momento é de grande preocupação com a formação e o desenvolvimento da opinião pública também na área mercadológica, mas a produção caminha em desencontro a esse anseio, apresentando cada vez menos publicações com esse enfoque.

Conforme a legislação brasileira da área de relações públicas, essa atividade profissional reivindica para si a gestão do processo de gerenciamento da opinião pública. Contudo, a maioria dos autores que tratam do assunto, seja em livros ou em teses, aparenta não conseguir aprofundar a reflexão sobre o tema - isso quando o abordam.

Dentre abordagens que poderiam embasar a amplificação de pesquisas na área, destacam-se investigações possíveis: no contexto da comunicação organizacional; no âmbito da esfera pública; junto a obras não exclusivamente autorais e na área das 
relações públicas, mas também em coletâneas de maior abrangência temática e junto a periódicos científicos relacionados ao tema. Em todas essas dimensões, haveria uma significativa riqueza de análise dado o caráter multidisciplinar do tema. 0 trabalho aqui relatado, portanto, pode alavancar outras reflexões para o entendimento de uma dimensão tão relevante afeta às relações públicas.

\section{REFERÊNCIAS}

AUGRAS, Monique. Opinião pública: teoria e pesquisa. Petrópolis, RJ: Vozes, 1974.

BARDIN, Laurence. Análise de conteúdo. Lisboa: Edições 70, 1977.

BLUMER, Gerbert. A massa, o público e a opinião pública. In: COHN, Gabriel (org.). Comunicação e indústria cultural. São Paulo: Companhia Editora Nacional, 1978.

CATTO, Camilo. Persuasão, manipulação e opinião pública: dos clássicos às críticas. Cadernos da Escola de Comunicação. Curitiba, v.1, n.6, p.1-9, 2008.

CHILDS, Harwood L. Relações públicas, propaganda e opinião pública. Rio de Janeiro: FGV, 1976.

FARIAS, Luiz Alberto de. Opiniões voláteis: opinião pública e construção de sentido. São Bernardo do Campo: Metodista, 2019.

FORTES, Waldyr Gutierrez. Relações públicas no campo do transmarketing: contribuição à administração estratégica praticada nas organizações. 1993. Tese (Doutorado em Ciências da Comunicação) - Escola de Comunicações e Artes, Universidade de São Paulo, São Paulo, 1993.

HABERMAS, Jürgen. Mudança estrutural da esfera pública. Rio de Janeiro: Tempo Brasileiro, 2003.

HOHLFELDT, Antonio Carlos. Os campos das relações públicas e das teorias da comunicação. In: MOURA, Cláudia Peixoto de; FOSSATTI, Nelson (org.). Práticas acadêmicas em relações públicas. processos, pesquisas, aplicações. Porto Alegre: Sulina, 2011.

MAQUIAVEL, Nicolau. O príncipe. São Paulo: Hemus, 1977.

MORAES, Roque. Uma tempestade de luz: a compreensão possibilitada pela análise textual qualitativa. Porto Alegre: PUCRS; Mimeo, 2002.

RICHARDSON, Roberto Jarry. Pesquisa social: métodos e técnicas. São Paulo: Atlas, 1999.

SILVA, Christiani Margareth de Menezes e. 0 conceito de doxa (opinião) em Aristóteles. Linha D'Água, São Paulo, v.29, n.2, p.43-67, 2016.

SILVA, Daniel Reis. Relações públicas, ciência e opinião: lógicas de influência na produção de (in)certezas. 2017. Tese (Doutorado em Comunicação Social) - Faculdade de Filosofia e Ciências Humanas, Universidade Federal de Minas Gerais, Belo Horizonte, 2017. 